\title{
PIRÓLISE RÁPIDA DE CASCA DE SOJA: COMPARAÇÃO ENTRE O BIO-ÓLEO PROVENIENTE DE REATOR DE LEITO FLUIDIZADO E OS VAPORES GERADOS NA PIRÓLISE ANALÍTICA
}

\author{
T. J. P. OLIVEIRA ${ }^{1}$, C. R. CARDOSO ${ }^{2}$, W. S. CARVALHO ${ }^{3}$ E C. H. ATAÍDE ${ }^{4 *}$ \\ ${ }^{1,3,4}$ Universidade Federal Uberlândia, Faculdade de Engenharia Química \\ ${ }^{2}$ Universidade Federal do Triângulo Mineiro, Departamento de Engenharia de Alimentos \\ E-mail para contato: chataide@ufu.br
}

\begin{abstract}
RESUMO - A otimização das condições do processo de pirólise rápida, requer uma metodologia analítica rápida e confiável, de modo a nos fornecer informações preliminares para o processo de produção de bio-óleo. O micropirolisador acoplado a um GC/MS é amplamente empregado para se realizar uma avaliação eficiente dos vapores gerados na pirólise de biomassa. O objetivo deste trabalho foi investigar as diferenças entre a composição do bio-óleo, obtido através do processo pirólise rápida de casca de soja em um reator de leito fluidizado; e a composição dos vapores obtidos na análise de micropirólise. O bio-óleo mostrou-se uma mistura complexa, rica em fenóis, 2,2 metilciclopentanone e tetradecano. Nos vapores foram identificados como principais compostos o 1,3-pentadieno, ácido acético, fenóis e tetradecano. As diferenças entre a composição do bio-óleo e dos vapores, provavelmente se devem a ocorrência de reações secundárias, diferentes taxas de aquecimento e a etapa de condensação dos vapores.
\end{abstract}

\section{INTRODUÇÃO}

Com a crescente preocupação com o aquecimento global devido às emissões de dióxido de carbono, a redução gradativa dos combustíveis fósseis e a procura por um fornecimento seguro de combustíveis, o interesse por fontes renováveis e sustentáveis de energia é crescente. A biomassa lignocelulósica é a única fonte economicamente sustentável de carbono para a produção de combustíveis líquidos renováveis ou produtos químicos (Huber et al., 2006).

A pirólise é uma forma de converter biomassa em energia e ocorre pela decomposição térmica direta dos componentes da biomassa, na ausência parcial ou total de oxigênio, visando à produção de gases, sólidos e líquidos (Bridgwater, 2012). O bio-óleo é um produto de interesse, visto que apresentam alto poder calorífico, é facilmente transportado e armazenado, possui baixo conteúdo de nitrogênio e enxofre, além de ser fonte de produtos químicos (Apaydin-Varol et al., 2007). As principais características do processo de pirólise rápida são: curtos tempos de aquecimento das partículas e de residência para os vapores que se formam dentro do reator, elevadas taxas de aquecimento, elevados coeficientes de transferência de calor e massa, temperaturas moderadas da fonte de aquecimento, entre 400 e $600^{\circ} \mathrm{C}$ (Goyal et al., 2008). O líquido orgânico (bio-óleo) é uma 


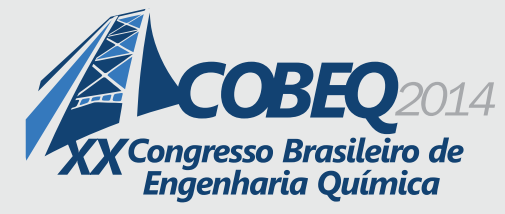

19 a 22 de outubro de 2014

Florianópolis/SC

mistura de centenas de compostos orgânicos cujas propriedades físicas e químicas dependem da natureza e da composição da biomassa original, do método e das condições de produção. Os objetivos deste trabalho foram investigar as diferenças entre a composição do bio-óleo, obtido através do processo pirólise rápida de casca de soja em um reator de leito fluidizado e a composição dos vapores obtidos na análise de pirólise analítica (Py-GC/MS) e estudar a viabilidade do uso da pirólise rápida para converter a casca de soja em combustíveis ou compostos de valor agregado.

\section{MATERIAIS E MÉTODOS}

\subsection{Análises Imediata e Elementar, Composição Química e Poder Calorífico}

A análise imediata da casca de soja foi realizada de acordo com a NBR 8112/1986. Para realizar a análise elementar utilizou-se o equipamento Vario Micro Cube, marca Elementar. A composição química do da casca de soja foi determinada. O teor de extrativos foi estimado segundo a NBR 14853/2010. As porcentagens de holocelulose (celulose e hemicelulose) foram estimadas segundo o procedimento descrito por Leplé et al. (2007). O teor de lignina insolúvel foi obtido através do procedimento descrito pela norma NBR 7989/2010. O poder calorífico da biomassa foi determinado, em um calorímetro da marca IKA, modelo C200, segundo a norma NBR 8633/84. A Tabela 1 mostra os resultados das análises mencionadas para a casca de soja.

Tabela 1 - Características físico-químicas da casca de soja

\begin{tabular}{ccccc}
\hline Análise Imediata (\%) & Materiais Volatéis & cinzas & Carbono Fixo & \\
Umidade & 79,02 & 5,21 & 7,37 & \\
7,75 & & & & \\
Análise Elementar (\%) & $\mathrm{H}$ & 1,96 & 52,95 & 0,06 \\
$\mathrm{C}$ & 5,76 & & & \\
39,27 & & & & \\
Análise Química (\%) & Lignina Insolúvel & Lignina Solúvel & Holocelulose & Cinzas \\
Extrativos & 1,76 & 3,07 & 76,22 & 4,34 \\
14,61 & & & & \\
Poder Calorifico (MJ/Kg) & & & & \\
17,73 & & & & \\
\hline
\end{tabular}

\subsection{Análises Termogravimétricas TGA/DTG}

As análises termogravimétricas para as amostras de casca de soja pura foram realizadas em um analisador termogravimétrico Shimadzu, modelo TGA/DTG-60H. Medições não isotérmicas foram realizadas sob fluxo contínuo de atmosfera inerte de nitrogênio gasoso de alta pureza 99.999, a taxa de $30 \mathrm{~mL} / \mathrm{min}$. Amostras de aproximadamente $14 \mathrm{mg}$ foram utilizadas nas análises. Foram realizados experimentos dinâmicos nos quais o material foi aquecido a $100^{\circ} \mathrm{C}$, com taxa de aquecimento de $50^{\circ} \mathrm{C} / \mathrm{min}$, e mantido a essa temperatura por $30 \mathrm{~min}$, para reduzir a umidade. Logo após, o material foi aquecido a $900^{\circ} \mathrm{C}$ empregando cinco diferentes taxas de aquecimento: $10,15,20$ e $25^{\circ} \mathrm{C} / \mathrm{min}$ 


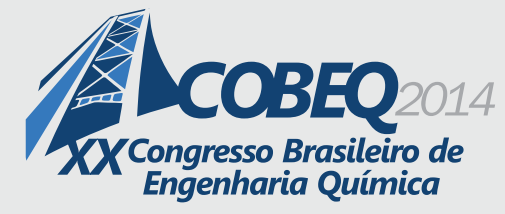

(triplicata). Os dados referentes aos primeiros 30 minutos foram desconsiderados, assim as variações de massa devido à perda de água não foram consideradas. As análise foram realizadas nas mesmas condições utilizadas por Cardoso et al. (2011).

\subsection{Micropirólise}

A micropirólise rápida das amostras foi realizada em um micropirolisador CDS 5200. O micropirolisador consiste de uma resistência de platina que pode ser aquecida até $1200{ }^{\circ} \mathrm{C}$ com taxa de aquecimento máxima de $20^{\circ} \mathrm{C} / \mathrm{ms}$. Uma pequena quantidade (na ordem de $\mu \mathrm{g}$ ) de casca de soja foi inserida em um capilar de quartzo, juntamente com lã de vidro (inerte), para impedir que a amostra se movimentasse e assim permanecesse no centro do capilar; a amostra foi posicionada na resistência de platina e levada ao micropirolisador. O gás inerte empregado na micropirólise foi hélio (pureza 99,999). A taxa de aquecimento utilizada nas análises foi de $20{ }^{\circ} \mathrm{C} / \mathrm{ms}$. As temperaturas de reação foram de 450, 550, 650 e $750{ }^{\circ} \mathrm{C}$. Após atingir a temperatura final a resistência permaneceu aquecida por 10s. As condições de pirólise adotadas, taxa de aquecimento e tempo de aquecimento da resistência foram escolhidas de acordo com literatura prévia (Lu et al., 2011b; Cardoso; Ataíde. 2013). Para cada amostra, as análises foram realizadas em triplicata para garantir a reprodutibilidade dos resultados. O processamento de dados foi realizado com a biblioteca de compostos NIST versão 05 e apenas os compostos com índice de similaridade (IS) maior que $80 \%$ foram registrados.

\subsection{Reator de Leito Fluidizado}

Os leitos fluidizados borbulhantes têm a vantagem de ser uma tecnologia bem conhecida, de simples construção e exploração, controle de temperatura e transferência de calor eficiente. Por isso, é importante o conhecimento de aspetos relativos à cinética química, termodinâmica, mecânica dos fluidos, transferência de calor e massa. A escolha da tecnologia de leito fluidizado se deve à sua versatilidade e aos custos atrativos de implantação (Bridgwater, 2012).

No presente trabalho foi utilizada uma planta piloto de pirólise rápida projetado na Faculdade de Engenharia Química da Universidade Federal de Uberlândia - MG, conforme mostra a Figura 1. A unidade experimental é composta por um reator de aço inox, com $5 \mathrm{~mm}$ de espessura, $1 \mathrm{~m}$ de altura e $0,078 \mathrm{~m}$ de diâmetro interno. No corpo do reator, junto a sua base, há uma placa sinterizada de bronze, com $0,080 \mathrm{~m}$ de diâmetro e $3 \mathrm{~mm}$ de espessura, utilizada como distribuidor de gás. No corpo do reator estão instalados 4 (quatro) pontos de aquisição de temperatura (conexões 1/4" NPT fêmea), para o acoplamento de termopares do tipo K (Chromel-Alumel) para monitoramento da temperatura no interior do reator. Um desses termopares é acoplado a um controlador de temperatura para ajuste do set-point. O sistema de alimentação é composto por uma rosca sem fim acoplado a um silo, onde é armazenada a biomassa. Conectado ao topo do reator de leito fluidizado, tem-se um sistema de separação gás-sólido, constituído por um ciclone, que tem como finalidade a remoção dos sólidos presentes nos vapores gerados pelo processo de pirólise rápida de biomassa. Na saída dos vapores do ciclone (overflow), há um condensador. Esses vapores gerados pela pirólise trocam calor com o fluido de refrigeração que ocupa o interior da camisa do condensador, promovendo a condensação dos vapores em bio-óleo a $-5^{\circ} \mathrm{C}$. O reator de leito fluidizado é aquecido por meio de resistências elétricas rígidas modulares na forma de $\mathrm{U}$, que contornam a parede externa do reator, com potência de $2000 \mathrm{~W}$ 
(trifásica), operando a uma faixa de temperatura de 400 a $700{ }^{\circ} \mathrm{C}$.

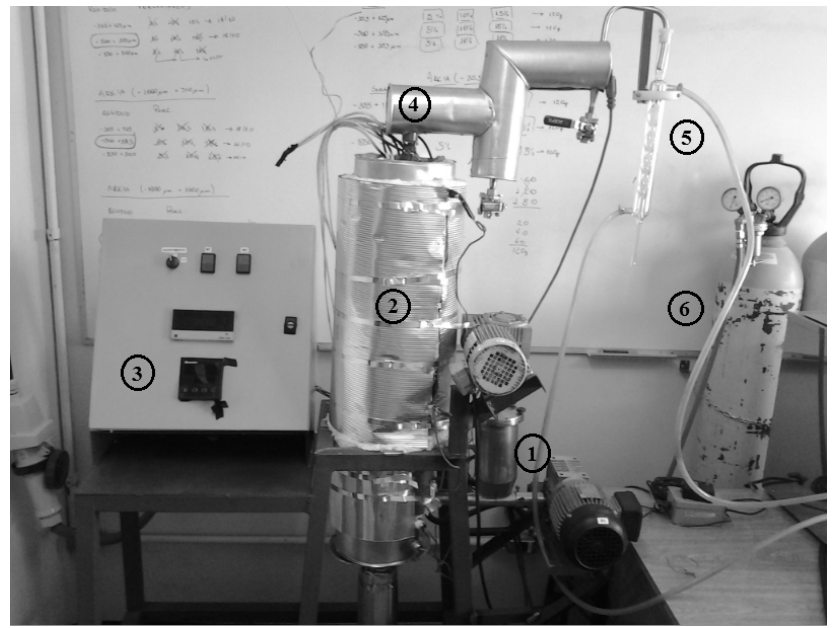

Figura 1: Unidade experimental: (1) Alimentador; (2) Leito fluidizado; (3) Painel de instrumentação; (4) Ciclone; (5) Condensador; (6) Nitrogênio.

\subsection{Pirólise Rápida em um Reator de Leito Fluidizado}

Inicialmente o reator foi carregado com $800 \mathrm{~g}$ de material inerte (areia), com a finalidade de garantir homogeneidade da mistura e elevado coeficientes de transferência de calor. Essas características são fundamentais para a cinética de decomposição térmica da biomassa. Em seguida o reator foi aquecido até atingir a temperatura set-point de $550{ }^{\circ} \mathrm{C}$. A velocidade superficial do gás de fluidização (nitrogênio) no interior do reator foi de 1,5 m/s. Em seguida, biomassa foi alimentada ao reator a uma taxa de 4,0 Kg/h. Os vapores gerados pela pirólise foram condensados a temperatura de $5{ }^{\circ} \mathrm{C}$. O óleo pirolítico foi dissolvido em clorofórmio e analisado empregando-se a técnica de cromatografia gasosa acoplada à espectrometria de massas (GC/MS).

O bio-óleo obtido pelo processo de pirólise rápida foi analisado com o auxilio de um cromatográfo gasoso/espectrômetro de massas (GC/MS QP2010 Plus). A coluna capilar utilizada para as analises foi a Rtx-1ms $(30 \mathrm{~m} \times 0.25 \mathrm{~mm} \times 0.25 \mu \mathrm{m})$. Gás hélio com elevado grau de pureza $(99,999)$ foi utilizado como gás de arraste $\mathrm{O}$ processamento de dados foi realizado de forma similar ao adotado para as análises de micro pirólise.

\section{RESULTADOS E DISCUSSÕES}

\subsection{TDG/DTG}

As curvas de perdas de massa ou TG (visualizada na escala da esquerda) e derivada de perda massa ou DTG (visualizada na escala da direita) para a casca de soja em diferentes taxas de aquecimento, conforme mostra a Figura 2. Observa-se o efeito da taxa de aquecimento na decomposição térmica da casca de soja. A taxa de aquecimento modifica as posições da curva TG e 


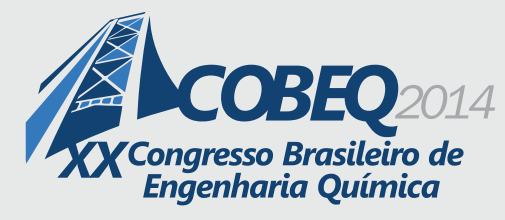

19 a 22 de outubro de 2014

Florianópolis/SC

DTG, além disso, um aumento na amplitude do pico DTG, indicando um acréscimo da taxa de degradação máxima. Com o aumento da taxa de aquecimento, a decomposição passa a ocorrer em temperaturas mais altas.
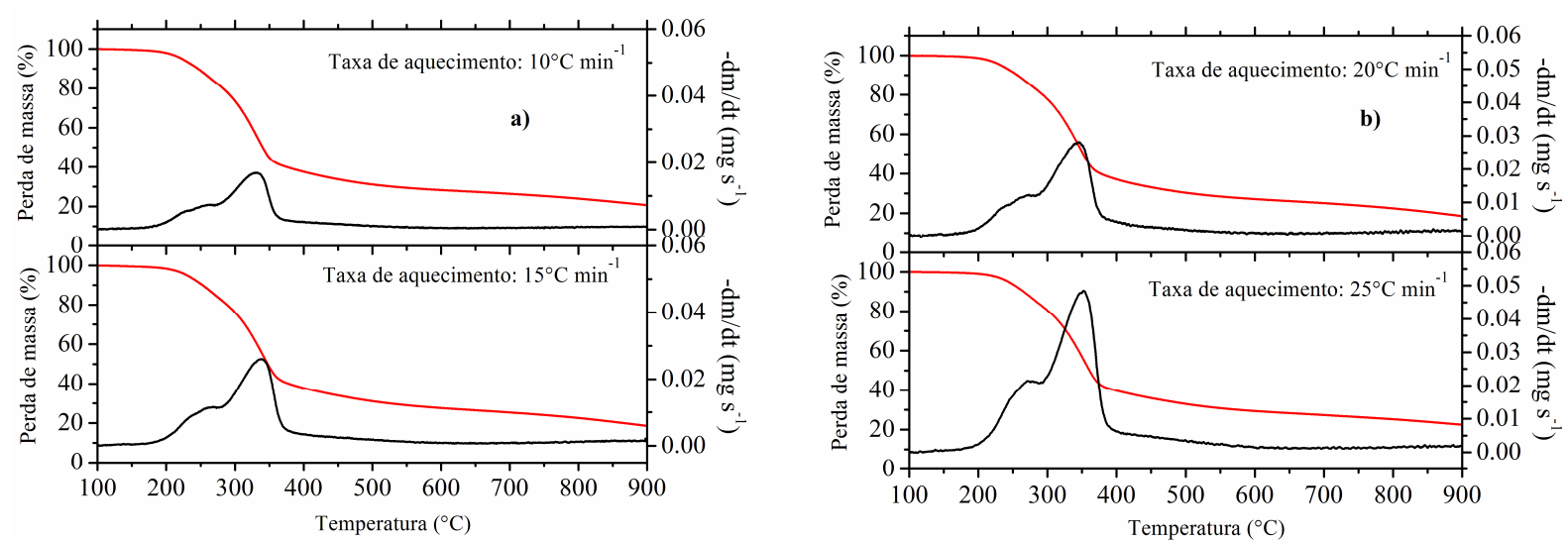

Figura 2 - Curvas TG e DTG para a casca de soja: a) 10 e $15^{\circ} \mathrm{C} \mathrm{min}^{-1}$; b) 20 e $25 \mathrm{C} \mathrm{min}^{-1}$.

\subsection{Micropirólise}

Os cromatogramas referentes à pirólise analítica da casca de soja a 450, 550, 650 e $750{ }^{\circ} \mathrm{C}$, conforme mostra a Figura 3. A $450{ }^{\circ} \mathrm{C}$, os principais compostos identificados nos vapores de pirólise analítica da casca de soja foram ácido acético, acido carbônico, limoneno e hexadecano. A $500{ }^{\circ} \mathrm{C}, \mathrm{o}$ ácido acético continua sendo o composto de maior pico de área, porém verificamos a presença de hidrocarbonetos de cadeia longa como o ciclohexano e tetradecano. A $650{ }^{\circ} \mathrm{C}$, ocorreu a formação de hidrocarbonetos, como 1,3-pentadieno, limoneno, hexadecano, tetradecano e olenitrila. $\mathrm{O}$ pico referente ao ácido acético é menos expressivo comparado a temperaturas de 450 e $550{ }^{\circ} \mathrm{C}$. A $750{ }^{\circ} \mathrm{C}$, observa-se hidrocarbonetos (1,3-pentadieno, tolueno, tetradecano) e aldeído (etanodial) como os principais componentes gerados na micropirolise. $\mathrm{O}$ ácido acético aparece de forma menos expressiva em relação a 450 e $550{ }^{\circ} \mathrm{C}$, porém em maior proporção comparado a $650{ }^{\circ} \mathrm{C}$. Compostos fenólicos foram gerados apenas para temperaturas acima de $550{ }^{\circ} \mathrm{C}$, porém de forma menos significativa. Em todas as faixas de temperaturas observa-se a presença de alguns traços de compostos importantes como furfural, 2-furano-metanol, $2(5 \mathrm{H})$ furanone, benzenos e toluenos.

\subsection{Pirólise Rápida de Casca de Soja}

Os resultados da análise de cromatografia do bio-óleo da casca de soja via GC/MS, os quais foram feitos em triplicata, conforme mostra a Figura 4. O bio-óleo de casca de soja mostrou-se, uma mistura complexa constituída por uma grande variedade de compostos orgânicos a partir de diversos grupos químicos. Os principais compostos presentes no bio-óleo com elevados picos de área incluem, compostos fenólicos (fenol, 2-metil-fenol e 4-metil-fenol), acetonas (2-metil-2-ciclopentanona) e hidrocarbonetos (azuleno, tetradecano e heptadecano). 

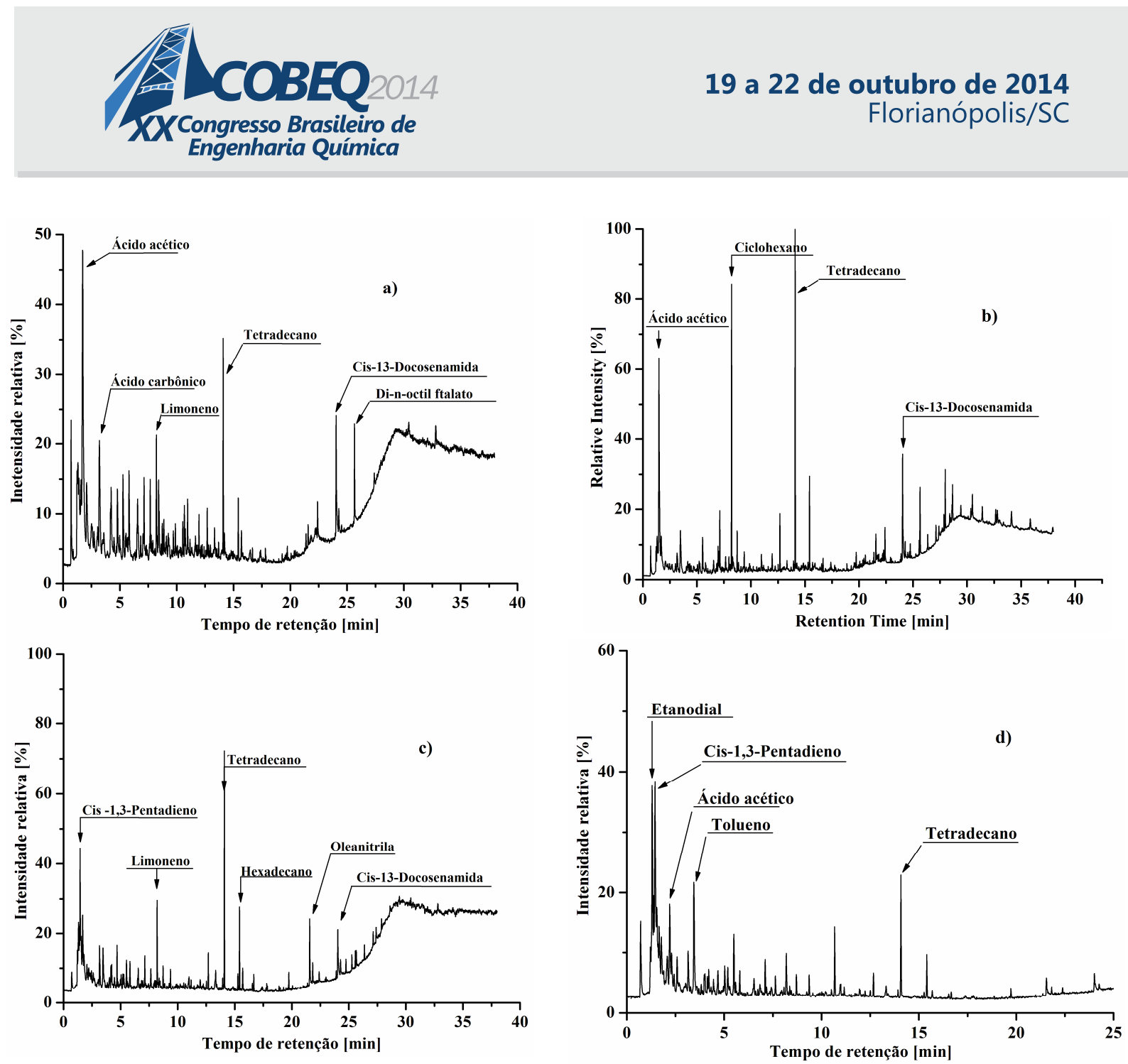

Figura 3 - Cromatogramas dos vapores gerados na micropirólise da casca de soja: (a) $450{ }^{\circ} \mathrm{C}$, (b) 550 ${ }^{\circ} \mathrm{C}$, (c) $650{ }^{\circ} \mathrm{C}$ e (d) $750{ }^{\circ} \mathrm{C}$.

No caso do bio-óleo de casca de soja, destacamos os três principais compostos: fenol $(14,88 \%)$, 2-metil-fenol (7,59\%) e 4-metil-fenol (12,55\%). Estes compostos de alto valor econômico podem ter benefícios significativos para a indústria química, que utiliza fenóis para a síntese de resina e medicamentos (Effendi et al, 2008). As resinas fenólicas são tipicamente resinas poliméricas com ligação cruzada, o custo do fenol e a disponibilidade do mesmo estão ligados ao petróleo, produtos industriais que utilizam fenol, tais como resinas de fenol-formaldeído ou fenólicos são relativamente caros (Quan Bu et al, 2012). A elevada presença de alcoóis pode ser originária da degradação térmica da lignina. A pirólise provoca o craqueamento térmico dessas biomoléculas em compostos orgânicos simples. A decomposição da lignina, por pirólise, produz metoxifenóis dos quais monolignóis (guaiacol e siringol) são proeminentes. É uma das principais fontes de fenóis presentes nos bio-óleos (Pankaj K. Kanaujia et al., 2014).

O bio-óleo é uma mistura complexa de compostos e os componentes de identificação depende do solvente utilizado e das condições de análise, como a coluna de cromatografia gasosa. As diferenças entre a composição dos vapores de micro pirólise e o bio-óleo podem ser atribuídas, 


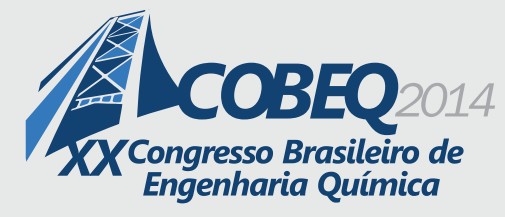

19 a 22 de outubro de 2014

Florianópolis/SC

principalmente, às diferentes taxas de aquecimento que ocorrem na planta piloto e no micropirolisador. As condições de reações na planta piloto possuem fatores de difícil controle, tendo como consequência a ocorrência de reações secundarias no interior do reator e diferentes tempos de residência. Outra possível razão para as diferenças observadas é a efetiva condensação dos vapores, que ocorre na planta piloto de pirolise rápida.

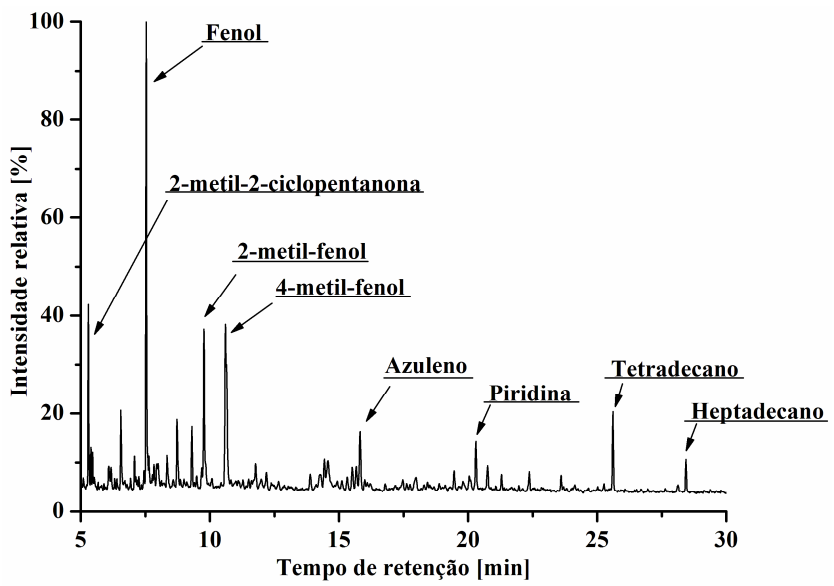

Figura 4 - Cromatograma do bio-óleo da casca de soja.

\section{CONCLUSÕES}

Neste presente trabalho, o bio-óleo produzido na planta piloto de pirólise rápida projetada e instalada na Faculdade de Engenharia Química da Universidade Federal de Uberlândia (MG) foi caracterizado. Os principais componentes do bio-óleo foram analisados no GC/MS e, mostram que este bio-óleo pode ser usado como uma fonte alternativa de produtos químicos de valor agregado, pois é rico em compostos fenólicos, utilizados na síntese de resinas e medicamentos na indústria farmacêutica. Foram observadas diferenças entre os compostos gerados na micro pirólise de casca de soja e os compostos gerados na unidade piloto com reator de leito fluidizado. Tais diferenças podem ser atribuídas principalmente à ocorrência de reações secundarias no interior do reator de leito fluidizado e à efetiva condensação dos vapores, que ocorre na planta piloto de pirólise rápida. Mudanças no sistema de condensação têm sido propostas, de forma a melhorar a eficiência de condensação dos vapores gerados na planta piloto.

\section{AGRADECIMENTOS}

Os autores agradecem a CAPES (Coordenação de Aperfeiçoamento de Pessoal de Nível Superior), a CEMIG (Companhia Energética de Minas Gerais), ao CNPq (Conselho Nacional de Desenvolvimento Científico e Tecnológico) e a Fundação de Amparo à Pesquisa do Estado de Minas Gerais (FAPEMIG) pelos recursos concedidos no Projeto de Participação Coletiva em Eventos Técnicos-Científicos (PCE-00082-14). 


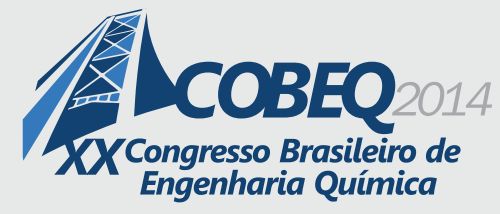

\section{REFERÊNCIAS}

APAYDIN-VAROL, E., ERSAN, P., AYŞE E.P. Slow pyrolysis of pistachio shell. Fuel, v. 86, p. 1892-1899, 2007.

BRIDGWATER, A.V. Review of fast pyrolysis of biomass and product upgrading. Biomass and bioenergy, v. 38, p. 68-94, 2012.

CARDOSO, C.R, MIRANDA, M.R., SANTOS, K.G., ATAÍDE, C.H. Determination of kinetic parameters and analytical pyrolysis of tobacco waste and sorghum bagasse. J. Anal. Appl. Pyrol., v. 92, p. 392-400, 2011.

CARDOSO, C.R., ATAÍDE, C.H. Analytical pyrolysis of tobacco residue: Effect of temperature and inorganic additives, J. Anal. Appl. Pyrol., v. 99, p. 49-57, 2013.

GOYAL, H.B., DIPTENDU, S., SAXENA, R.C. Bio-fuels from thermochemical conversion of renewable resources: A review. Renew. Sust. Energ. Rev., v. 12, p. 504-517, 2008.

HUBER, G.W., IBORRA, S., CORMA, A. Synthesis of transportation fuels from biomass: chemistry, catalysts, andengineering. Chem. Rev., v. 106, p. 4044-4098, 2006.

LEPLÉ, J. C.; DAUWE, R.; MORREEL, K.; STORME, V.; LAPIERRE，C.; POLLET, B.; NAUMANN, A.; KANG, K. Y.; KIM, H.; RUEL, K.; LEFĖEBVRE, A.; JOSELEAU, J. P.; GRIMAPETTENATI, J.; RYCKE, R.; ANDERSSON-GUNNERAS, S.; ERBAN, A.; FEHRLE, I.; PETITCONIL, M.; KOPKA, J.; POLLE, A.; MESSENS, E.; SUNDBERG, B.; MANSFIELD, S. D.; RALPH, J.; PILATE, G.; BOERJAN, W. Downregulation of cinnamoyl-coenzyme a reductase in poplar: multiple-level phenotyping reveals efects on cell wall polymer metabolism and structure. The Plant Cell, v. 19, p. 3669-3691, 2007.

LU, Q.; DONG, C.; ZHANG, X.; TIAN, H.; YANG, Y.; ZHU, X. Selective fast pyrolysis of biomass impregnated with $\mathrm{ZnCl}_{2}$ to produce furfural: analytical Py-GC/MS study. J. Anal. Appl. Pyrol, v. 90, p. 204-212, 2011.

PANKAJ K. K., SHARMA, Y.K., GARG, M.O., DEEPENDRA, T., RAGHUVIR, S. Review of analytical strategies in the production and upgrading of bio-oils derived from lignocellulosic biomass. J. Anal. Appl. Pyrol, v. 105, p. 55-74, 2014.

QUAN, B., HANWU, L., SHOUJIE, R., LU, W., ZHANG, Q., TANG, J., RUAN, R.. Production of phenols and biofuels by catalytic microwave pyrolysis of lignocellulosic biomass. Bioresour. Technol. v. 108, p. 274-279, 2012. 